\title{
Paraspinal Transposition Flap for Reconstruction of Sacral Soft Tissue Defects: A Series of 53 Cases from a Single Institute
}

\author{
Sandipan Gupta ${ }^{1}$, Debarati Chattopadhyay ${ }^{1}$, Akhilesh Kumar Agarwal ${ }^{1}$, Goutam Guha ${ }^{1}$, \\ Nirjhar Bhattacharya ${ }^{2}$, Pawan K Chumbale ${ }^{1}$, Souradip Gupta ${ }^{1}$, Marang Buru Murmu ${ }^{1}$ \\ ${ }^{I}$ Department of Plastic Surgery, Medical College, Kolkata, India \\ ${ }^{2}$ Department of General Surgery, Nilratan Sircar Medical College and Hospital, Kolkata, India
}

\begin{abstract}
Study Design: Case series.
Purpose: To describe paraspinal transposition flap for coverage of sacral soft tissue defects.

Overview of Literature: Soft tissue defects in the sacral region pose a major challenge to the reconstructive surgeon. Goals of sacral wound reconstruction are to provide a durable skin and soft tissue cover adequate for even large sacral defects; minimize recurrence; and minimize donor site morbidity. Various musculocutaneous and fasciocutanous flaps have been described in the literature. Methods: The flap was applied in 53 patients with sacral soft tissue defects of diverse etiology. Defects ranged in size from small (6 $\mathrm{cm} \times 5 \mathrm{~cm}$ ) to extensive $(21 \mathrm{~cm} \times 10 \mathrm{~cm})$. The median age of the patients was 58 years (range, $16-78$ years).

Results: There was no flap necrosis. Primary closure of donor sites was possible in all the cases. The median follow up of the patients was 33 months (range, 4-84 months). The aesthetic outcomes were acceptable. There has been no recurrence of pressure sores.

Conclusions: The authors conclude that paraspinal transposition flap is suitable for reconstruction of large sacral soft tissue defects with minimum morbidity and excellent long term results.
\end{abstract}

Keywords: Transposition flap; Pressure ulcer; Sacral defect

\section{Introduction}

Soft tissue defects in the sacral region are mostly caused by pressure sores, the other causes being radiation necrosis, pilonidal sinus and tumor excision. Sacral pressure sores are a major cause of morbidity in paraplegic patients, and recurrence rates are high. Irrespective of the etiology, these defects pose a major challenge to the reconstructive surgeon. Goals of reconstruction of such sacral defects are to 1) provide a durable skin and soft tissue cover adequate for even large sacral defects; 2) minimize recurrence; and 3) minimize donor site morbidity. A variety of reconstructive procedures for coverage of these defects have been described. Here we describe a cutaneous flap for resurfacing sacral soft tissue defects, and present the results of this technique in 53 patients with sacral defects of varying dimensions and various etiologies.

Received Mar 1, 2013; Revised Jun 8, 2013; Accepted Sep 1, 2013

Corresponding author: Sandipan Gupta

Department of Plastic Surgery, Medical College, 2nd floor, Green Building, 88, College Street,

Kolkata 700073, West Bengal, India

Tel: +91-9830037199, Fax: +91-22287165, E-mail: sandipangupta4@gmail.com 


\section{Materials and Methods}

We used this paraspinal transposition flap for reconstruction of sacral pressure sores and other sacral defects in 53 patients during a period of seven years between 2005 and 2012. Of these, 39 patients had sacral pressure sores, eight patients had pilonidal sinus, five patients had radionecrosis and one patient had excision of malignant melanoma. Thirty-one of these patients were ambulatory, nine were bedridden and 13 patients were paraplegic. The median age of the patients was 58 years (range, $16-78$ years). The dimension of the sacral defects ranged from $6 \mathrm{~cm} \times 5 \mathrm{~cm}$ to as large as $21 \mathrm{~cm} \times 10 \mathrm{~cm}$. In all the cases, unilateral flaps were used to cover the defects. Table 1 shows the demographic data of the patients in the study.

\section{The surgical technique}

The sacral wound was debrided with freshening of the wound margins and excision of the pseudosac in the case of pressure sores. The dimensions of the defect were measured. A transversely oriented, pear-shaped skin and

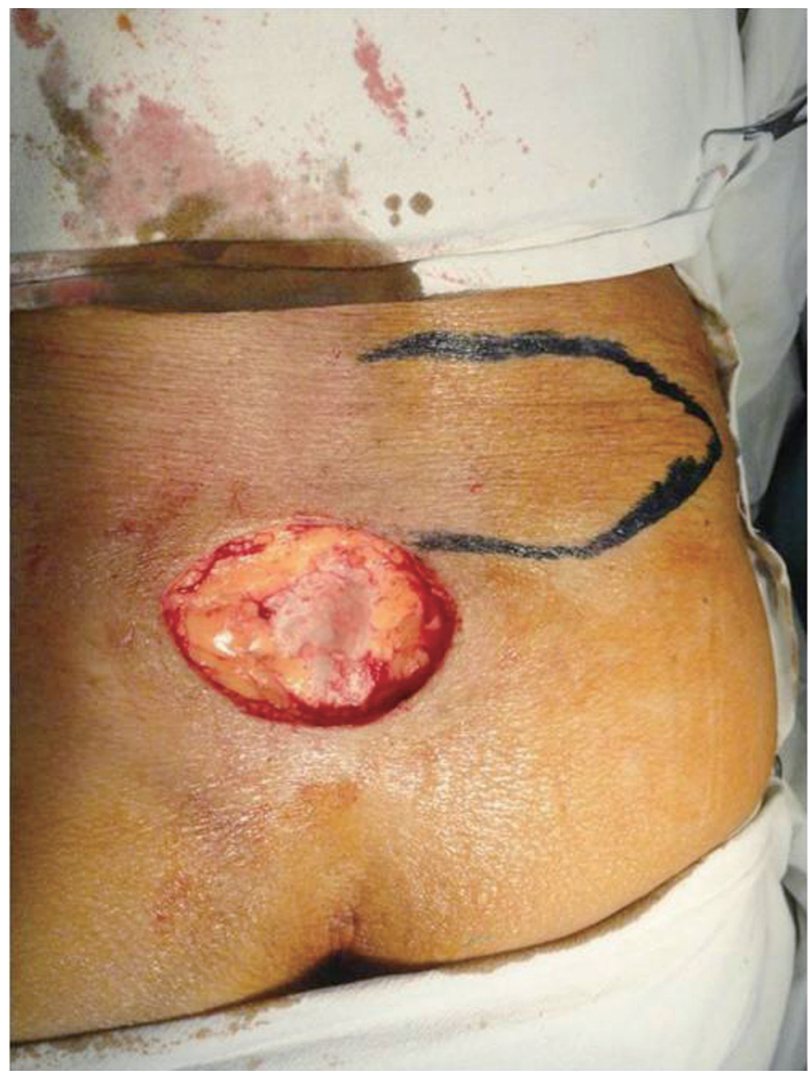

Fig. 1. Outline of the flap. subcutaneous tissue flap of adequate dimensions was designed with a broad base near the midline and gradually tapering laterally (Fig. 1). The lower cutaneous incision started at the upper margin of the wound in the midline. The upper cutaneous incision was placed at a point such that the breadth of the flap was the same as the breadth of the wound. Laterally the flap could be extended up to a vertical line joining the posterior axillary fold and the greater trochanter, if required, as in the case of large defects. The flap was raised from the lateral to the medial side through the plane between the subcutaneous fat and the fascia covering the gluteus maximus muscle, up to a point $2 \mathrm{~cm}$ away from the midline to preserve the ipsilateral perforator vessels. However, it could be safely dissected up to the midline if required, as the flap is viable even by contralateral perforators. The flap was then transposed and inset into the defect (Fig. 2). The donor site was closed primarily by undermining, up to the natal fold. A suction drain was placed beneath the flap and in the donor area.

1) The vascular basis and innervation of the flap [1] The skin and subcutaneous tissue flap described above is based on the lumbar and sacral paraspinal perforators. The lateral cutaneous branches of the dorsal rami of the four lumbar arteries pierce the thoracolumbar fascia to supply the overlying skin. Posterior branches of the lateral sacral arteries supply the skin between the midline and a line joining the posterior superior iliac spine and the coccyx. The skin of the lower dorsolateral trunk is supplied by musculocutaneous perforators arising from the intercostal and lumbar arteries. There are dense inter-

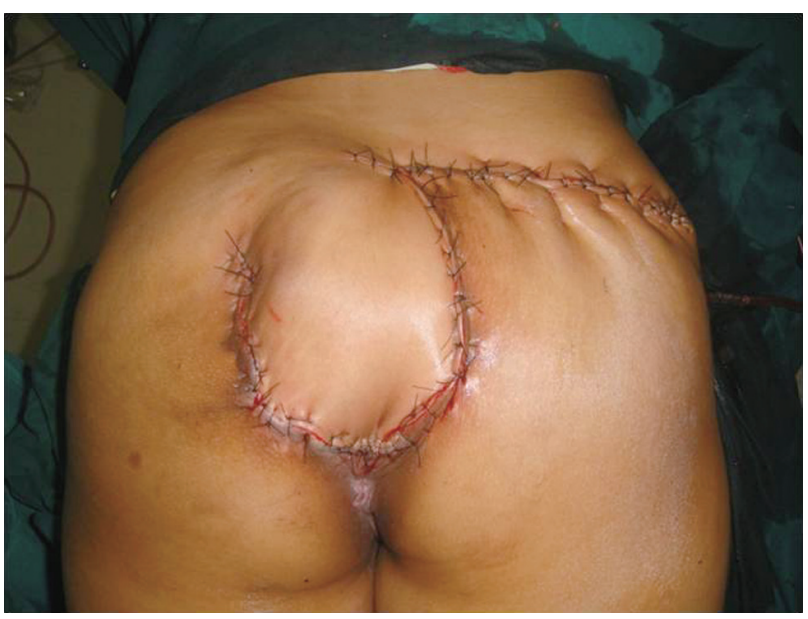

Fig. 2. Peroperative picture after flap inset. 
Table 1. Patient characteristics

\begin{tabular}{|c|c|c|c|c|c|c|c|}
\hline $\begin{array}{l}\text { Serial } \\
\text { No. }\end{array}$ & $\begin{array}{l}\text { Age } \\
\text { (yr) }\end{array}$ & Sex & Cause of sacral defect & $\begin{array}{l}\text { Size of defect } \\
(\mathrm{cm} \times \mathrm{cm})\end{array}$ & $\begin{array}{l}\text { Clinical status } \\
\text { of patient }\end{array}$ & Complications & $\begin{array}{l}\text { Follow-up } \\
\text { (mo) }\end{array}$ \\
\hline 1 & 64 & $\mathrm{~F}$ & Pressure sore & $6 \times 8$ & Ambulatory & - & 84 \\
\hline 2 & 22 & M & Pressure sore & $7 \times 6$ & Paraplegic & - & 72 \\
\hline 3 & 70 & $\mathrm{~F}$ & Radionecrosis & $10 \times 11$ & Ambulatory & - & 64 \\
\hline 4 & 72 & M & Pilinidal sinus & $6 \times 6$ & Ambulatory & - & 60 \\
\hline 5 & 67 & M & Pressure sore & $10 \times 9$ & Bedridden & - & 60 \\
\hline 6 & 16 & M & Pressure sore & $11 \times 10$ & Ambulatory & - & 57 \\
\hline 7 & 50 & $\mathrm{~F}$ & Pressure sore & $7 \times 11$ & Ambulatory & - & 56 \\
\hline 8 & 47 & $M$ & Pilinidal sinus & $8 \times 8$ & Ambulatory & - & 53 \\
\hline 9 & 75 & $\mathrm{~F}$ & Pressure sore & $9 \times 7$ & Paraplegic & - & 52 \\
\hline 10 & 71 & $\mathrm{~F}$ & Radionecrosis & $6 \times 11$ & Ambulatory & - & 52 \\
\hline 11 & 68 & $\mathrm{~F}$ & Malignant melanoma & $8 \times 9$ & Ambulatory & - & 50 \\
\hline 12 & 60 & $M$ & Pressure sore & $10 \times 10$ & Bedridden & - & 50 \\
\hline 13 & 25 & $\mathrm{~F}$ & Pressure sore & $6 \times 6.5$ & Paraplegic & - & 48 \\
\hline 14 & 18 & $\mathrm{~F}$ & Pressure sore & $8.5 \times 9.5$ & Ambulatory & - & 46 \\
\hline 15 & 20 & $M$ & Pressure sore & $17 \times 9$ & Ambulatory & - & 45 \\
\hline 16 & 45 & $M$ & Pilinidal sinus & $13 \times 9$ & Ambulatory & - & 44 \\
\hline 17 & 50 & $M$ & Pressure sore & $11 \times 6$ & Ambulatory & - & 43 \\
\hline 18 & 63 & $M$ & Pressure sore & $12 \times 5.5$ & Paraplegic & - & 42 \\
\hline 19 & 18 & $M$ & Pressure sore & $11 \times 10.5$ & Ambulatory & - & 42 \\
\hline 20 & 21 & M & Pressure sore & $7 \times 11$ & Ambulatory & - & 39 \\
\hline 21 & 72 & $\mathrm{~F}$ & Pressure sore & $6.5 \times 14$ & Bedridden & - & 38 \\
\hline 22 & 26 & $\mathrm{~F}$ & Pressure sore & $8 \times 11$ & Ambulatory & - & 36 \\
\hline 23 & 65 & $M$ & Pressure sore & $14 \times 8.5$ & Paraplegic & - & 36 \\
\hline 24 & 59 & $M$ & Pressure sore & $16 \times 10$ & Bedridden & - & 36 \\
\hline 25 & 33 & $M$ & Pilinidal sinus & $7.5 \times 8$ & Ambulatory & - & 34 \\
\hline 26 & 30 & $M$ & Pressure sore & $11 \times 12$ & Paraplegic & - & 33 \\
\hline 27 & 58 & $M$ & Pressure sore & $14 \times 5.5$ & Bedridden & - & 33 \\
\hline 28 & 42 & $F$ & Pressure sore & $9.5 \times 7.5$ & Paraplegic & - & 32 \\
\hline 29 & 51 & $\mathrm{~F}$ & Pressure sore & $10 \times 10$ & Ambulatory & - & 30 \\
\hline 30 & 35 & M & Pilinidal sinus & $6 \times 7.5$ & Ambulatory & - & 30 \\
\hline 31 & 22 & $\mathrm{~F}$ & Pressure sore & $4.5 \times 10$ & Ambulatory & - & 26 \\
\hline 32 & 60 & $M$ & Pressure sore & $8 \times 6$ & Paraplegic & - & 24 \\
\hline 33 & 62 & $\mathrm{~F}$ & Radionecrosis & $21 \times 10$ & Ambulatory & Wound dehiscence & 24 \\
\hline 34 & 36 & M & Pressure sore & $5 \times 11$ & Ambulatory & - & 24 \\
\hline 35 & 55 & M & Pressure sore & $7 \times 11$ & Ambulatory & - & 21 \\
\hline 36 & 75 & $M$ & Pressure sore & $10 \times 12$ & Paraplegic & - & 20 \\
\hline 37 & 23 & $M$ & Pressure sore & $6 \times 8.5$ & Ambulatory & - & 18 \\
\hline 38 & 78 & M & Pressure sore & $7 \times 10$ & Bedridden & - & 15 \\
\hline 39 & 64 & $M$ & Pilinidal sinus & $15 \times 8$ & Ambulatory & - & 12 \\
\hline 40 & 66 & $\mathrm{~F}$ & Radionecrosis & $11 \times 9$ & Ambulatory & - & 12 \\
\hline
\end{tabular}


Table 1. Continued

\begin{tabular}{|c|c|c|c|c|c|c|c|}
\hline $\begin{array}{l}\text { Serial } \\
\text { No. }\end{array}$ & $\begin{array}{l}\text { Age } \\
\text { (yr) }\end{array}$ & Sex & Cause of sacral defect & $\begin{array}{l}\text { Size of defect } \\
\quad(\mathrm{cm} \times \mathrm{cm})\end{array}$ & $\begin{array}{c}\text { Clinical status } \\
\text { of patient }\end{array}$ & Complications & $\begin{array}{l}\text { Follow-up } \\
\qquad(\mathrm{mo})\end{array}$ \\
\hline 41 & 69 & M & Pressure sore & $6 \times 6$ & Paraplegic & - & 11 \\
\hline 42 & 26 & $\mathrm{~F}$ & Pressure sore & $8 \times 5$ & Ambulatory & - & 11 \\
\hline 43 & 72 & $\mathrm{~F}$ & Pressure sore & $11 \times 10$ & Bedridden & - & 10 \\
\hline 44 & 64 & M & Pilinidal sinus & $5 \times 4.5$ & Ambulatory & - & 9 \\
\hline 45 & 73 & $\mathrm{~F}$ & Pressure sore & $7 \times 8.5$ & Bedridden & - & 9 \\
\hline 46 & 56 & $\mathrm{~F}$ & Pressure sore & $9 \times 9$ & Paraplegic & - & 8 \\
\hline 47 & 66 & $\mathrm{~F}$ & Radionecrosis & $14 \times 9$ & Ambulatory & - & 8 \\
\hline 48 & 72 & M & Pressure sore & $6 \times 5$ & Paraplegic & - & 7 \\
\hline 49 & 69 & M & Pressure sore & $17 \times 9$ & Bedridden & - & 6 \\
\hline 50 & 29 & M & Pressure sore & $15 \times 10$ & Ambulatory & - & 6 \\
\hline 51 & 53 & M & Pilinidal sinus & $8 \times 4.5$ & Ambulatory & - & 5 \\
\hline 52 & 65 & $\mathrm{~F}$ & Pressure sore & $12 \times 7$ & Paraplegic & - & 5 \\
\hline 53 & 25 & M & Pressure sore & $6 \times 6$ & Ambulatory & - & 4 \\
\hline
\end{tabular}

F, female; $M$, male.

connections and anastomoses between all these vessels, which account for the large dimensions of flap possible in our patients.

The skin in the flap area is supplied by the lateral branches of lumbar and sacral dorsal spinal rami. The lumbar dorsal spinal rami cross the iliac crest to reach the gluteal skin, some reach as far as the level of the greater trochanter. The sacral dorsal spinal rami supply the posterior gluteal skin. Thus, except in paraplegic patients the flap is sensate.

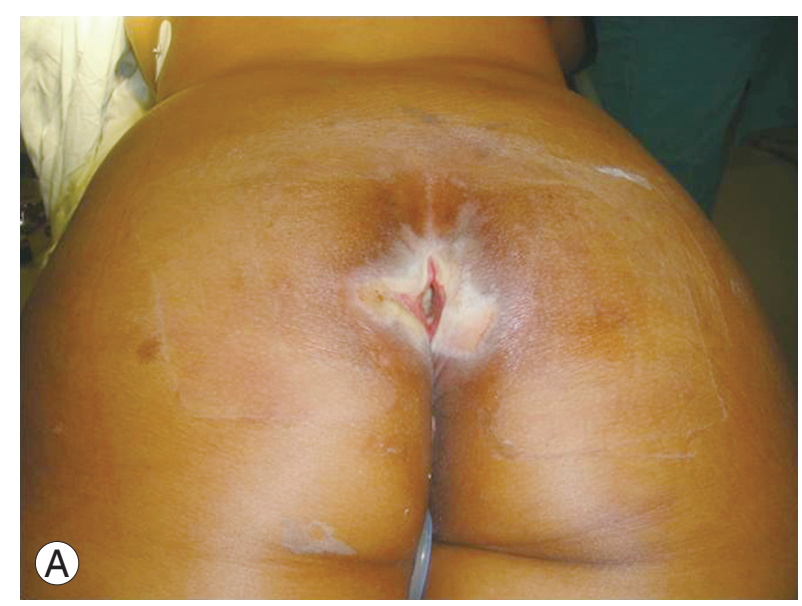

Fig. 3. Results of the procedure in sacral pressure sore. (A) Preoperative photograph. (B) Postoperative outcome after one year.

\section{Results}

There was no flap necrosis in our series. Primary closure of donor sites was possible in all the cases. One patient with a sacral ulcer secondary to radionecrosis developed minor wound dehiscence at the donor site due to wound

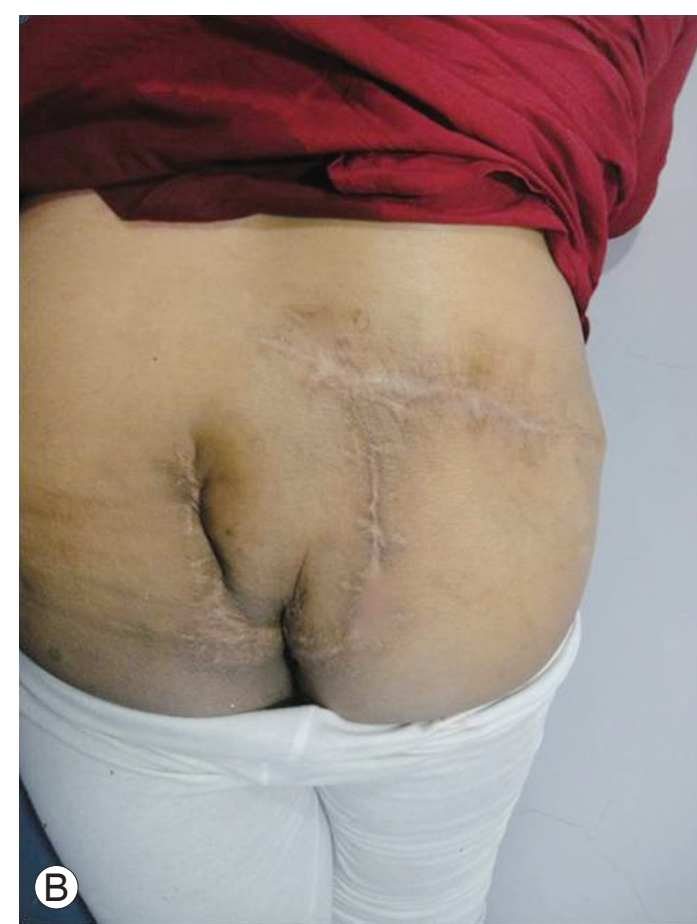


infection, which healed by secondary union. The median follow up of the patients was 33 months (range, 4-84 months). The aesthetic outcomes were acceptable (Fig. 3). There has been no recurrence of pressure sores.

\section{Discussion}

The reconstruction of sacral soft tissue defects is a challenging task and is associated with the risk of wound complications and recurrence. Local transposition flaps are the mainstay of reconstruction of sacral pressure sores and other sacral soft tissue defects [2]. The options for coverage include musculocutaneous flaps, perforatorbased fasciocutaneous flaps, cutaneous flaps and free flaps.

The musculocutaneous flaps available are the V-Y gluteus maximus advancement flap (ipsilateral or contralateral) and its many variations. Bilateral gluteus maximus musculocutaneous flaps are reserved for larger sacral defects [2]. Gluteus maximus musculocutaneous flaps are reliable where filling of an extensive cavity with adequate bulk is essential, but they entail significant blood loss, require longer operating time and interfere with the function of the gluteus maximus muscle, which may be clinically significant in the ambulatory patient, in addition to limiting future reconstructive possibilities in the case of recurrence.

The fasciocutaneous flaps include the transverse lumbar flap and the more recent superior gluteal artery perforator (SGAP) flap. The transverse lumbar flap described by Rawat and Mathur [3] may not be adequate to cover large sores. Another possible disadvantage is that in the case of bilateral flaps the suture line lies in the pressure area. Choi et al. [4] reported a single case of a lumbosacral defect after spinal surgery using the transverse lumbosacral rotational flap.

Perforator based flaps have been proven to be effective for reconstruction of sacral sores. The SGAP flap is a pedicled fasciocutaneous flap which preserves the integrity of the gluteus muscles [5]. However, the drawbacks of the SGAP flap are an extended surgical time, a steep learning curve, and the need for microsurgical instruments and loupe magnification [6].

The transverse lumbosacral back flap described by Hill et al. [7] has the disadvantages of limited size, requirement of a skin graft for coverage of the donor site, and need for a back-cut in some cases; also the vascularity of the flap tip may be less dependable than that of a musculocutaneous flap [8]. It is recommended for small sacral defects [2].

The thoracolumbar-sacral cutaneous flap described by Vyas et al. [9] for resurfacing sacral pressure sores is a large, medially based arterialized flap raised from the posterior thoracic, lumbar and gluteal regions. This flap is outlined starting at the inferior edge of the defect, curving around the flank, and ending up toward the interscapular region [9]. The procedure suffers from the drawbacks of the requirement of extensive dissection, resulting in significant blood loss and large scars.

Korambayil et al. [10] described the propeller flap method based on the superior gluteal and parasacral artery perforators for reconstruction of sacral and ischial defects in 11 patients. The major disadvantage of the perforator propeller flap is that the flap is mostly insensate and hence associated with a higher risk of wound recurrence.

The flap described in this article has the following advantages: 1) the technique is simple, with a sound anatomical basis; 2) this is a skin and subcutaneous tissue flap, thus the gluteal muscle is preserved as a future reconstructive option to cover recurrent defects or failed flaps; 3 ) the flap is suitable for both small as well as large sacral defects (the largest defect in our series was 21 $\mathrm{cm} \times 10 \mathrm{~cm})$; 4) there is less operative blood loss compared to musculocutaneous flaps; 5) there is no requirement of a skin graft for the donor area, and the donor site morbidity is minimal; 6) availability of sufficient skin cover helps to avoid skin tension; 7) the technique is less time-consuming compared to the musculocutaneous and SGAP flaps; 8) the flap is sensate unlike some of the previously described flaps, hence the results are durable with no recurrence of defect in our series; and 9) the aesthetic outcomes are acceptable. The preservation of gluteus maximus muscle integrity and function in our technique is especially important in non-paralysed patients who require full function of the gluteal muscles for recovery of ambulation. Furthermore, the use of this flap preserves the entire contralateral side, which may be used as a future donor site in case of recurrence.

\section{Conclusions}

In our series of patients, large sacral defects were reconstructed by our technique using single flaps, with durable 
and favourable results. In our experience, the flap described in this article offers a reliable method for coverage of sacral pressure sores and other sacral defects.

\section{Conflict of Interest}

No potential conflict of interest relevant to this article was reported.

\section{References}

1. Standring S. Gray's anatomy: the anatomical basis of clinical practice. 40th ed. Philadelphia: Churchill Livingstone; 2008.

2. Foster RD. Pressure sores. In: Mathes SJ, editor. Plastic surgery. 2nd ed. Philadelphia: Saunders Elsevier; 2006. p.1317-53.

3. Rawat SS, Mathur BS. Transverse lumbar flap for sacral bed sores. Plast Reconstr Surg 1991;88:154-8.

4. Choi SJ, Lee CB, Park HT, Park JH, Lee HS, Kim YJ. Treatment for the lumbosacral soft tissue defect after spine surgery. Asian Spine J 2010;4:44-7.
5. Leow M, Lim J, Lim TC. The superior gluteal artery perforator flap for the closure of sacral sores. Singapore Med J 2004;45:37-9.

6. Ozmen S, Kandal S, Findikcioglu F, Mentes B. Superior gluteal artery perforator flap: an alternative in the treatment of complicated pilonidal sinus. Gazi Med J 2006;17:176-8.

7. Hill HL, Brown RG, Jurkiewicz MJ. The transverse lumbosacral back flap. Plast Reconstr Surg 1978;62: 177-84.

8. Hill HL Jr. Transverse lumbosacral back flap. In: Strauch B, Vasconez LO, Hall-Findlay EJ, editors. Grabb's encyclopedia of flaps. 2nd ed. Philadelphia: Lippincott-Raven; 1998. p.1643.

9. Vyas SC, Binns JH, Wilson AN. Thoracolumbarsacral flaps in the treatment of sacral pressure sores. Plast Reconstr Surg 1980;65:159-63.

10. Korambayil PM, Allalasundaram K, Balakrishnan T. Perforator propeller flaps for sacral and ischial soft tissue reconstruction. Indian J Plast Surg 2010;43: 151-7. 